\title{
Investigative Study towards Development of K-Jawi Presentation Tool
}

\author{
Sim Liew Fong \\ Management and Science \\ University \\ Shah Alam, Malaysia
}

\author{
Kevin Loo Teow Aik \\ Management and Science \\ University \\ Shah Alam, Malaysia
}

\author{
Abdelrahman Osman \\ Elfaki \\ Management and Science \\ University \\ Shah Alam, Malaysia address
}

\author{
Md Gapar Md Johar \\ Management and Science \\ University \\ Shah Alam, Malaysia
}

\author{
Omar Amer Abuuabdalla \\ Management and Science \\ University \\ Shah Alam, Malaysia
}

\begin{abstract}
This presentation tool is an alternative way providing documentation in Jawi scripts. Its purpose is to simplify the usage for a user as one of the choices in presentation. It is because this application is equipped with basic functions and easy to comprehend. This application is user friendly and has an attractive standard and formatting toolbars composition and easy to handle. It can be used in education environment, and congruent used in discussion, conference that hooked with Jawi scripts directly or indirectly. This application will assist user to create an apprehending slide show. It provides the easy tool incorporate text like insert texts, background and image. This application is totally different with other presentation tools because it created specifically in Jawi scripts.
\end{abstract}

\section{Keywords}

Human Computer Interface, object-oriented; Jawi Presentation Tool; slideshow.

\section{INTRODUCTION}

Jawi is a traditional script that was used by older Malay generation before the invasion of British Empire in Tanah Melayu. Jawi script was brought by Islamic missionary from Arab. The other thing that contributes to the use of Jawi character was because Jawi characters are similar with the writing in the holy Quran but the differences is the Holy Quran is in Arabic but Jawi script is in Malay. [7]

It is important to preserve the Jawi script as it is an old Malay heritage. Most of the young generations today are not very familiar with Jawi and some do not even know how to read Jawi because of the lack of usage in day to day activities. Malay should make Jawi its own special writing. This shows how close Jawi is to the Malay culture, especially in Malaysia. [3], [15]

Wikipedia defined Presentation Tool as a computer software package which is used to display information, normally in the form of a slide show. It typically includes three major functions: an editor that allows text to be inserted and formatted, a method for inserting and manipulating graphic images; and a slide-show system to display the content. It gives user everything the user needs to produce a professional-look presentation. Presentation tools are widely used by business people, educators, students, and trainers and it is among the most common forms of persuasion to the technology. The slides on the presentation tools may contain images, text, audio clips, video and animations.

This project is to create the K-Jawi Presentation Tool. The Presentation Tool is helpful to those who want to make presentation in Jawi. It is also to simplify the usage of presenting their slide show in Jawi. K-Jawi Presentation Tool will be helpful for those who want to make presentation in Jawi. [12]. [13]

\section{PROBLEM IDENTIFICATION}

This project will be focusing on building the Jawi Presentation Tool. There are several problems why we need to carry of this project such as:

i) Non-existing presentation tool dedicated for Jawi Microsoft Office PowerPoint 2007, Sun Microsystems's Star Office 8 Impress, Sun Microsystems's OpenOffice.org 2.1 Impress and IBM's Lotus SmartSuite Freelance Graphics 9.8 are the popular presentation tool that available in the market. But all of the software above didn't support Jawi. [20]. [21]

ii) Difficulties in teaching Jawi without appropriate assisting tool. These days Jawi had been taught in traditional way such as writing on blackboard. With evolving technology available, an effective teaching tool can be used to make learning easier.[1], [7], [8], [9]

\section{OBJECTIVES}

The main objectives of this project development are to create a presentation tools in Jawi characters, as an aiding tools in teaching and learning environment and able to present the presentation slide by slide

\section{PROJECT SIGNIFICANCE}

It just not just merely typing Jawi but it is more like tools for documentation, making a report, portfolio and slideshow. The main purpose is user can view and interact with the system, hence understand more about Jawi writing and reading overall. 
This project can be used as learning and teaching tools in school, university, and in the office. Jawi is an easy language to learn and understand.

Presentation tools can be very useful in presenting information. Our mission is to aid user in presenting information in Jawi so that Jawi can be used widely and not restricted like before.

The significance of this project is to preserve the Jawi heritage among young generations. The developed project is used to simplify the usage of slide shows that consist of multiple slides and help the user to obtain full control while presenting their slides. Thus, this presentation tools are useful for delivering speeches because the user can utilize the text on the screen to the audience or to summarize his/her dialogue into more manageable ways. [11], [14], [16]

The K-Jawi Presentation Tool can optimize the usage of Jawi word in the routine work such as it will encourage more people to use the Jawi tools as an act of learning and teaching tool whether at home, school, university or in the office. Thus, it is an application to do documentation, reports, portfolios and slide shows and will assist the user in presenting information using Jawi.

\section{SCOPE OF THE PROJECT}

The scopes for this project are:

1. The menubar contains File, Edit, View, Format, Slide and Help.

2. The File contains New, Open, Close, Save, Save As, Print and Exit.

3. The Edit contains Undo, redo, Cut, Delete, Copy and Paste.

4. The View contains Toolbars and Statusbar.

5. The Format contains Image, Background and Text.

6. The Slide contains Add Slide, Remove Slide and Slideshow.

7. The Help contains About.

8. The Toolbar contains new, open, save, print, undo, redo, cut, copy and paste.

9. The Fontbar contains normal, bold, italic, text size and text color.

10. The Drawingbar contains rectangle, circle, text input, table, line, arrow, link line, bullet, frame color and fill color.

\section{LITERATURE REVIEW}

\subsection{Assumption}

Based on the analysis that had been carried out, the user must be familiar with Jawi script to understand how the presentation tool works. A very undeniable fact is that Jawi is used for Malay language only. Thus, the project is developed for users that are familiar with Jawi scripts and know how to read Jawi in order to use this application. Hence, people with basic IT knowledge are more likely to be interested in adopting this application into their system. [12], [13]

\subsection{Limitation}

However, there are certain limitations in this project such as limited image, audio and video format. The image file to be inserted can only be in JPEG File Interchange Format (.jpg). Meanwhile the audio file to be inserted can be only in MP3 audio file (.mp3). The video file inserted can only be in Windows Video File (.avi) or Movie File (.mpg). [2], [10]

\subsection{Current Situation}

Nowadays, presentation programs are very popular and widely used in helping the speaker to show his ideas and helping the participants with visual information which complements the talk. The most commonly known presentation program is Microsoft PowerPoint, although there are alternatives such as OpenOffice.org Impress and Apple's Keynote. However such presentation tool did not feature Jawi in their presentation tools. [18], [19]

\subsection{Related Literature}

Presentation tool (software): “..is a category of application program used to create sequence of words and pictures that tell a story or help support a speech or public presentation of information..". Presentation software can be divided into business presentation software and more general multimedia authoring tools, with dome products having characteristic"

\subsection{Related Products}

10 examples of the presentation tools had been analysed. These products and tools each have their significance or drawbacks. This review has helped the researchers to decide on approaches for the project development. The presentation tools are:

\subsubsection{PowerPoint 2010}

Microsoft is spicing up PowerPoint with new templates, animation effects, and image-editing tools. The current version, Microsoft Office PowerPoint 2007, which released in 2010 , brought major changes of the user interface and enhanced graphic capabilities.

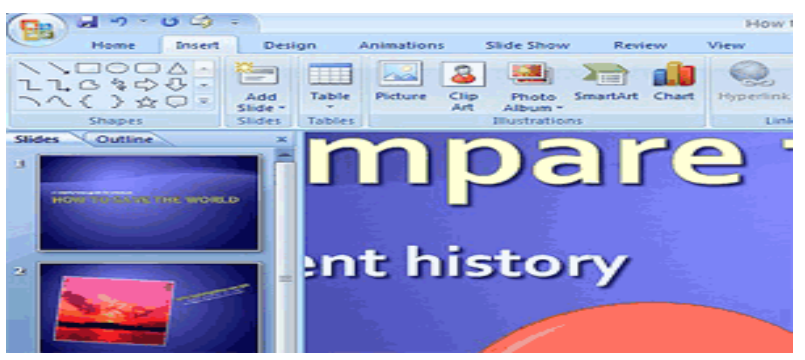

Figure 1: PowerPoint 2007 Screenshot

\subsubsection{Sun Microsystems Star Office 8: Impress}

Sun Microsystems StarOffice 8 is a solid productivity suite that costs a fraction of the price of its main competitor, Microsoft Office 2003. Impress, the counterpart of PowerPoint, got a facelift in this version. Sun admits to mimicking PowerPoint features to enhance compatibility and familiarity.

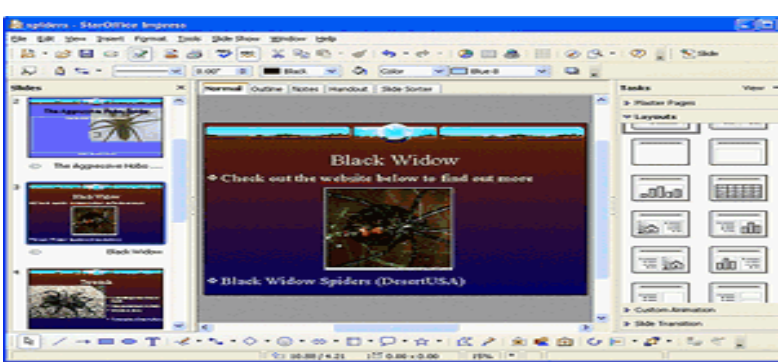

Figure 2: Star Office 8: Impress Screenshot 


\subsubsection{IBM's Lotus SmartSuite Freelance Graphics 9.8}

SmartSuite isn't as old as it sounds: 9.8 is not 1998, and this version was released in 2003. Although it's looking outdated and some feel it's been neglected by IBM , but SmartSuite has its own fans. It is cheaper than the other mainstream office suites. Freelance Graphics is available as part of the suite.

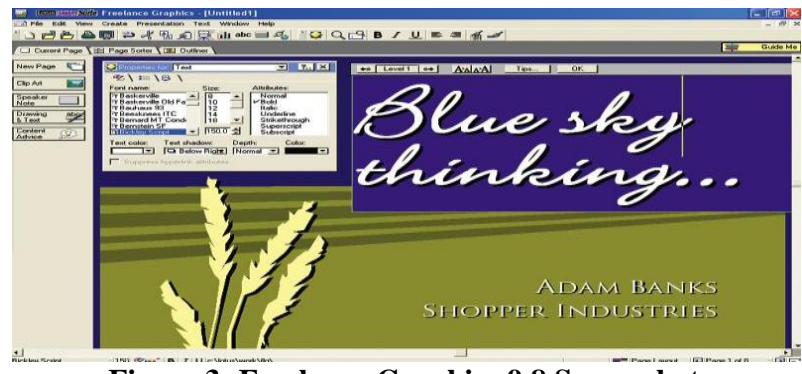

Figure 3: Freelance Graphics 9.8 Screenshot

\subsubsection{Apple Keynote 3}

Keynote 3 is the latest iteration of Apple's slide-show-creation software, released in conjunction with Apple iWork'06.It imports and exports all the file formats users likely to want. The main down-side is that it's only available for the latest Mac OS X. Other than that, it's priced affordably.

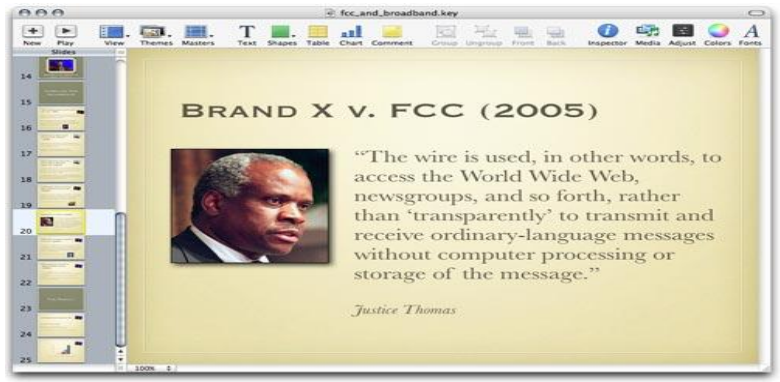

Figure 4: Apple Keynote 3 Screenshot

\subsubsection{Astound Presentation 8.0}

Astound Presentation 8.0 is a highly-rated, powerful, and easy-to-use alternative to PowerPoint. Reviewers even suggested using it to supplement PowerPoint, as it can add multimedia effects to imported .PPT files that Microsoft's program can't produce. Among its advanced features is a oneclick export to HTML or Dynamic HTML for plug-in-free web presentations.

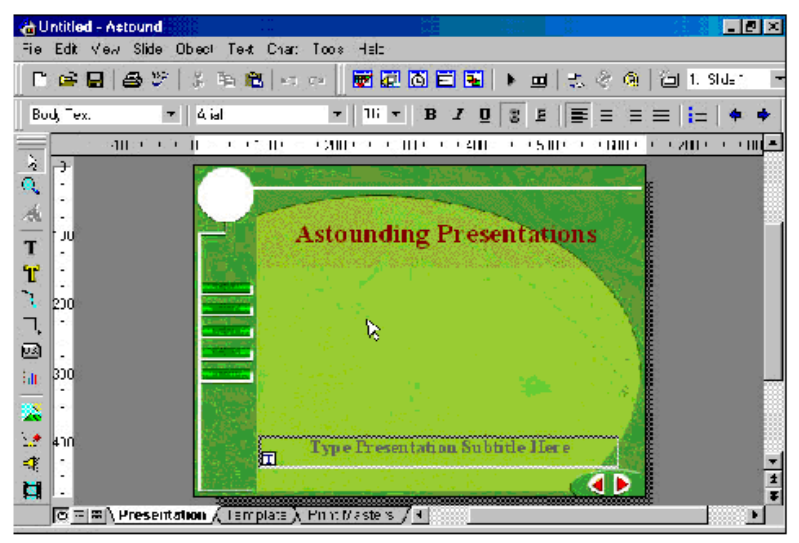

Figure 5: Astound Presentation 8.0 Screenshot

\subsubsection{Corel Presentations X3}

The new Corel Presentations X3 is a part of the Corel WordPerfect Office X3 Suite. Corel Presentations is a presentation-graphics program similar to Microsoft PowerPoint and OpenOffice.org's Impress. The current version, Corel Presentations X3, is released in $17^{\text {th }}$ January, 2006 for Windows platform.

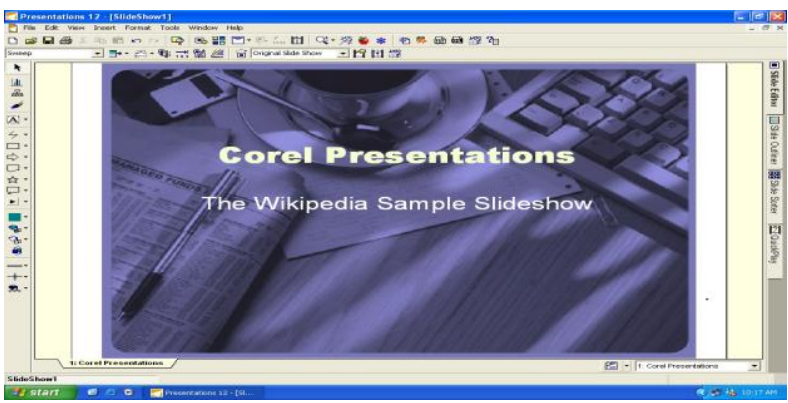

Figure 6: Corel Presentations X3 Screenshot

\subsubsection{GoBe Productive}

GoBe Productive is a highly-integrated office software package, by the same people who created the legendary Claris/AppleWorks package. It was a popular package for $\mathrm{BeOS}$, and is now available for Windows. A trial version is also available for download at the web.

\subsubsection{KPresenter}

KPresenter is a presentation application part of the KOffice. It can import PowerPoint files and export HTML pages. It's a fairly simple product, and doesn't have a very large array of templates and such included, but it's more than adequate for many people's presentation needs. As an open source project, it's likely to improve dramatically with age.

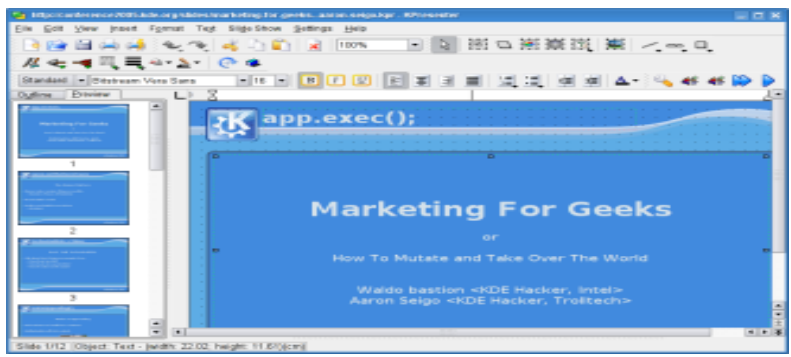

Figure 7: KPresenter Screenshot 


\subsubsection{AppleWorks}

AppleWorks (previously known as ClarisWorks) is a lowercost alternative to the more powerful presentationpackages. It's an easy-to-use multipurpose program, so users can use it for word processing, spreadsheets, and other things as well, which is one of the reasons to consider it as an inexpensive option, and graphics are one of its strong suits.

\subsubsection{MagicPoint}

MagicPoint is an open source presentation program. It uses a simple scripting language to define the content of a slideshow. MagicPoint was originally created in 1997, at a WIDE Project camp and known as tp, standing for TinyPoint, but in December the name was changed to MagicPoint. MagicPoint is completely free and is offered under absolutely no warranty from it's developers.

\subsection{The Comparison among Presentation Tools}

The following table shows the difference in terms of functionality of the 10 presentation tools as compared to the K-Jawi Presentation Tool. After thorough analysis, the K-Jawi Presentation Tool project now had a strong basement and several ideas, before entering the next stage of the development process.

Basically, three major functions needed in the making of the K-Jawi Presentation Tool: an editor that allows jawi text to be inserted and formatted, a method for inserting and manipulating graphic images and a slide-show system to display the content, and all this are in jawi environment. The technique on gathering the information and user requirements will be revealed in the next chapter.

Table 1: Presentation Tools' Comparison

\begin{tabular}{|c|c|c|c|c|c|}
\hline $\begin{array}{l}\text { Researc } \\
\text { h } \\
\text { IPresent } \\
\text { ation } \\
\text { Tool }\end{array}$ & Text & Graphic & $\begin{array}{l}\text { Audi } \\
\text { o }\end{array}$ & Video & $\begin{array}{l}\text { Animati } \\
\text { on }\end{array}$ \\
\hline $\begin{array}{l}\text { Microso } \\
\mathrm{ft} \\
\text { PowerP } \\
\text { oint } \\
2010\end{array}$ & $\begin{array}{l}\text { Sans } \\
\text { Serif }\end{array}$ & $\begin{array}{l}\text { JPEG, } \\
\text { GIF, or } \\
\text { BMP } \\
\text { format. }\end{array}$ & $\begin{array}{l}\text { MP3, } \\
\text { MIDI } \\
\text {, AU } \\
\text { and } \\
\text { WA } \\
\text { V } \\
\text { form } \\
\text { at }\end{array}$ & $\begin{array}{l}\text { MPEG } \\
\text { and } \\
\text { AVI } \\
\text { format }\end{array}$ & $\begin{array}{l}\text { Texts } \\
\text { Effect }\end{array}$ \\
\hline $\begin{array}{l}\text { Microsy } \\
\text { steMS } \\
\text { Star } \\
\text { Office 8: } \\
\text { Impress }\end{array}$ & $\begin{array}{l}\text { San } \\
\text { Serif }\end{array}$ & $\begin{array}{l}\text { JPEG, } \\
\text { GIF and } \\
\text { BMP }\end{array}$ & $\begin{array}{l}\text { AU, } \\
\text { CDA } \\
\text { MIDI } \\
\text {, and } \\
\text { WA } \\
\text { V } \\
\text { Audi } \\
\text { o }\end{array}$ & $\begin{array}{l}\text { MPEG } \\
\text { Quickti } \\
\text { me } \\
\text { Video } \\
\text { and } \\
\text { Vivo } \\
\text { Video } \\
\text { format }\end{array}$ & $\begin{array}{l}\text { Impress' } \\
\text { s } 59\end{array}$ \\
\hline
\end{tabular}

\begin{tabular}{|c|c|c|c|c|c|}
\hline $\begin{array}{l}\text { IBM's } \\
\text { Lotus } \\
\text { SmartSu } \\
\text { ite } \\
\text { Freelanc } \\
\text { e } \\
\text { Graphics } \\
9.8\end{array}$ & $\begin{array}{l}\text { Seri } \\
\mathrm{f}\end{array}$ & $\begin{array}{l}\text { JPEG, GIF } \\
\text { and BMP }\end{array}$ & $\begin{array}{l}\text { MIDI } \\
\text { and } \\
\text { WA } \\
\text { V }\end{array}$ & $\begin{array}{l}\text { AIM, } \\
\text { AVI,A } \\
\text { WM, } \\
\text { and } \\
\text { MOV } \\
\text { format }\end{array}$ & $\mathrm{BS}$ \\
\hline $\begin{array}{l}\text { Apple } \\
\text { Keynote }\end{array}$ & $\begin{array}{l}\text { Seri } \\
\mathrm{f}\end{array}$ & $\begin{array}{c}\text { BMP, } \\
\text { MacPaint, } \\
\text { PICT, } \\
\text { PNG, GIF, } \\
\text { TGA, } \\
\text { TIFF and } \\
\text { JPEG }\end{array}$ & $\begin{array}{l}\text { WA } \\
\text { V, } \\
\text { AIFF } \\
\text { AMR } \\
\text { and } \\
\text { AAC }\end{array}$ & $\begin{array}{l}\text { MOV, } \\
\text { MPEG } \\
\text { AVI } \\
\text { video } \\
\text { format }\end{array}$ & $\begin{array}{l}\text { FLC, } \\
\text { FlashM } \\
\text { edia }\end{array}$ \\
\hline $\begin{array}{l}\text { Astound } \\
\text { Presenta } \\
\text { tion }\end{array}$ & $\begin{array}{c}\text { Seri } \\
\mathrm{f}\end{array}$ & $\begin{array}{l}\text { TIF, EPS, } \\
\text { PCX, GIF, } \\
\text { BMP, } \\
\text { JPEG, } \\
\text { DIB, } \\
\text { CGM, } \\
\text { RLE, } \\
\text { PICT, } \\
\text { TGA, } \\
\text { WMF, } \\
\text { Metafile, } \\
\text { and Photo } \\
\text { CD image } \\
\text { formats }\end{array}$ & $\begin{array}{l}\text { WA } \\
\text { V, } \\
\text { AIFF } \\
\text { MIDI } \\
\text { and } \\
\text { CD- } \\
\text { Audi } \\
\text { o } \\
\text { soun } \\
\text { ds }\end{array}$ & $\begin{array}{l}\text { Micros } \\
\text { oft } \\
\text { Media, } \\
\text { Quick } \\
\text { Time, } \\
\text { MPEG } \\
\text { and } \\
\text { RealM } \\
\text { edia } \\
\text { format } \\
\text { s }\end{array}$ & $\begin{array}{c}\text { AWM } \\
\text { and } \\
\text { FLI } \\
\text { formats }\end{array}$ \\
\hline $\begin{array}{c}\text { Corel } \\
\text { Presenta } \\
\text { tions }\end{array}$ & $\begin{array}{l}\text { Seri } \\
\mathrm{f}\end{array}$ & $\begin{array}{l}\text { JPEG, } \\
\text { GIF and } \\
\text { BMP } \\
\text { format. }\end{array}$ & $\begin{array}{l}\text { WA } \\
\text { V, } \\
\text { MIDI } \\
\text { and } \\
\text { CD } \\
\text { soun } \\
\text { d } \\
\text { form } \\
\text { at }\end{array}$ & WMA & $\mathrm{Bd}$ \\
\hline $\begin{array}{l}\text { KPres } \\
\text { enter }\end{array}$ & $\begin{array}{l}\text { Seri } \\
\mathrm{f}\end{array}$ & $\begin{array}{l}\text { GIF, } \\
\text { JPEG, } \\
\text { BMP, } \\
\text { XPM, } \\
\text { XBM, } \\
\text { PNM, } \\
\text { PNG, EPS } \\
\text { and WMF }\end{array}$ & $\begin{array}{l}\text { WA } \\
\mathrm{V} \\
\text { and } \\
\text { MIDI }\end{array}$ & MPEG & $\mathrm{BS}$ \\
\hline $\begin{array}{l}\text { K- } \\
\text { Jawi } \\
\text { Prese } \\
\text { ntatio } \\
\text { n Tool }\end{array}$ & $\begin{array}{l}\text { jaw } \\
\mathrm{i}\end{array}$ & $\begin{array}{l}\text { JPEG, } \\
\text { GIF, BMP } \\
\text { and PNG } \\
\text { format. }\end{array}$ & $\mathrm{Bg}$ & 3 & 8 \\
\hline
\end{tabular}


The related works have been carefully reviewed in terms of the features set, ease of use and compatibility. The five elements of text, graphic, audio, video and animation has been carefully scrutinized and will be included as part of the features in the K-Jawi Presentation Tool. This application will be developed in the open source environment and will be compatible as it will be platform independent.

\section{RESEARCH DESIGN AND METHODOLOGY}

Software development approach is one of the major influences on the quality of the systems developed. In part at least, the object-oriented approach provides a mechanism for mapping from real-world problems to abstractions from which software can be developed effectively. In addition, object-oriented provides conceptual structures that help to deal with modeling complex system.

For K-Jawi Presentation Tool, the researches have used Unified Approach (UA) since the beginning of the project. This approach was adopted throughout the development life cycle serving as the main component of the project. However, this approach has developed from its preliminary forms as the K-Jawi Presentation Tool's development. During the process in development approach, relevant information to sculpt the K-Jawi Presentation Tool became available.[4], [5]

\subsection{Object Oriented Methodology}

Object-oriented design (OOD) is concerned with developing an object-oriented model of a software system to implement the identified requirements. OOD can yield the following benefits:

- Maintainability through simplified mapping to the problem domain, which provides for less analysis effort.

- Less complexity in system design, and easier verification by the user.

- Reusability of the design artifacts, which saves time and costs. [5]

For the K-Jawi Presentation Tool's project, we use the Unified Approach methodology. The reason why we use this methodology is because we believed that it is developing into an industry standard and what industry wants it. UML consists mainly of a graphical language to represent the concepts that we require in the development of an object-oriented information system. The aim of developing a new information system is to produce something that meets the needs of the people who will be using it. [5]

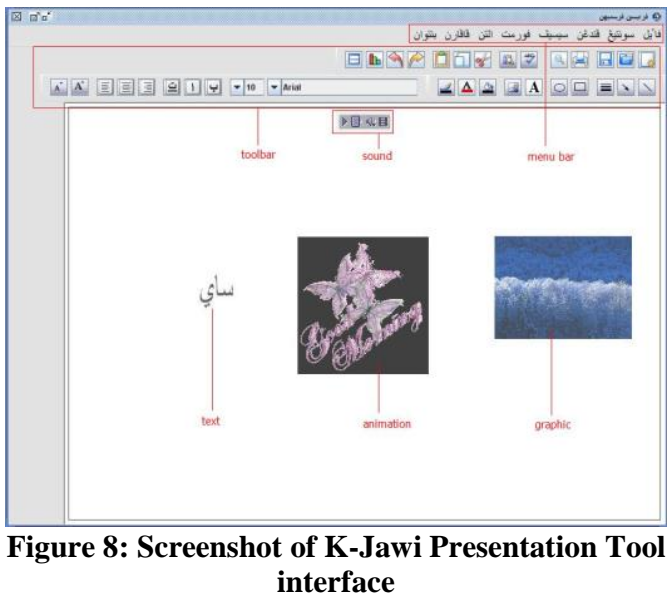

\section{TESTING RESULTS AND ANALYSIS}

The purpose of the testing phase is to ensure that the product, system, capability or recommendation performs and functions as defined in the client and technical requirements. Bugs and defects are fixed or resolved prior to executing user acceptance testing. User acceptance testing is needed during this phase to simulate production use and to prevent any potential problems post implementation. All documentation and processes are updated based on test results. [17]

\subsection{System Testing}

System Testing is on a complete, integrated system to evaluate the system's compliance with its specified requirements. System testing is within the scope of black box testing that should require no knowledge of the inner design of the code or logic

The purpose of integration testing is to detect any inconsistencies between the software units that are integrated together (called assemblages) or between any of the assemblages and the hardware. The testing result will show whether the entire system specifications and objectives are achieved. The systems tests perform are as below:

This test was performed, and the interface functions according to the requirements. All function in the K-Jawi Presentation Tool is responding with the correct action, and in reasonable time. [6]

\subsection{User Acceptance Testing}

A sample of 40 respondents ranging from friends, and potential users were chosen with different backgrounds to test the K-Jawi Presentation Tool. They were requested to test the K-Jawi Presentation Tool's functions such as open, edit and run presentation, and also to find any errors on the K-Jawi Presentation Tool. After testing the K-Jawi Presentation Tool, they were given a list of questionnaire to rate the K-Jawi Presentation Tool. They were also asked to give any comments or suggestions for the K-Jawi Presentation Tool.

\subsection{Testing Results and Analysis}

The first question on the questionnaire is to find out whether any of the respondents have been exposed to similar interface similar as the K-Jawi Presentation Tool. It clearly shows that all of the 40 respondents were never exposed interface similar to the K-Jawi Presentation Tool. The reasons are few Jawi software available and it is not as popular as English version products.

Next question is to observe whether the interface of the KJawi Presentation Tool is interesting. 59\% of respondents agree that the interface of The K-Jawi Presentation Tool is interesting. This is because it is not complicated with many features and every button is arranged very neat. $28 \%$ of respondents agree that the interface of The K-Jawi Presentation Tool is very interesting. The reason is because $\mathrm{K}$ Jawi Presentation Tool using jawi text as the interface and it is arranged from right-to-left at the top of Menu bar. Only 13\% of respondents have stated that they are not satisfied with the interface design and feel that the interface is not interesting. The reason is they feel uneasy to use the interface with jawi text.

Next is to determine whether the respondents are the icons understandable without the help tips. $82 \%$ of respondents voted that they understand the icons even without the help tips. It is because the icons in K-Jawi Presentation Tool are 
almost similar to other presentation tool. Meanwhile, $18 \%$ of the respondents feel uneasy without the help tip. It is because they are not familiar with the K-Jawi Presentation Tool and feel help tips is capable to assist them.

Next question is to observe whether all of the functions in the K-Jawi Presentation Tool are respond the correct action. All 40 respondents agree that all of the functions on the K-Jawi Presentation Tool are responding to the correct action. This mean all the functions are working and all the respondents are enjoy with the performance.

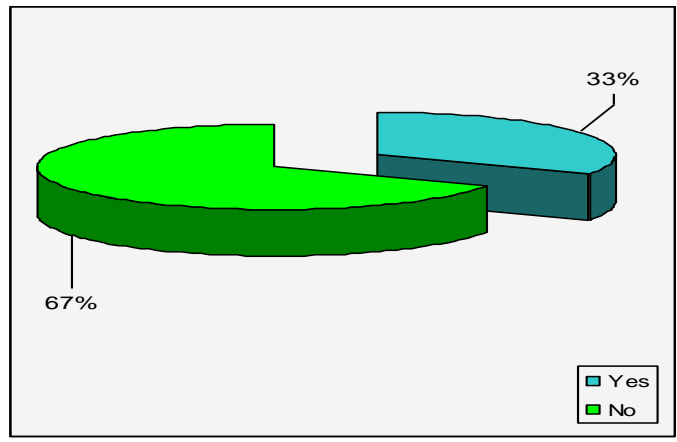

Figure 9: The Need for Other Function in The K-Jawi Presentation Tool

The chart above shows the percentage of users who has requested to add more features. Around $67 \%$ of respondents have requested to add additional features to the K-Jawi Presentation Tool. Respondents also gave some suggestions or recommendations to improve the K-Jawi Presentation Tool such to add multimedia elements such as audio, video and animation to make this presentation tool better. Remain users which is about $33 \%$ are agreed and satisfy with the current features.

One of the important steps in developing a system is the testing part. Testing will exercise the system in all possible ways. All four kinds of testing such as unit, integration, system and user acceptance testing have been done for the KJawi Presentation Tool. Different techniques is used to improve the Jawi Presentation Tool before been release as a final item.

\section{CONCLUSION AND FURTHER DEVELOPMENT}

\subsection{Conclusion}

The purpose of K-Jawi Presentation Tool is to create a presentation tools in Jawi characters. Hopefully, K-Jawi Presentation Tool will be a tool to be used by users as a platform to create presentations slides for presentation purposes.

Although this system has been successfully developed, this system needs further enhancement in features and functions to widen the scope. System limitation and further development were given as a reference for others who intend to extend this system.

\subsection{Further Development}

K-Jawi Presentation Tool can have further development on the following:

a) Image editing provided in the image tools

b) More support for table editing

c) Video and audio support.

\section{REFERENCES}

[1] Dewan Bahasa dan Pustaka 2004. Daftar Kata Bahasa Melayu, Rumi-Sebutan-Jawi, Jilid I dan II, Dewan Bahasa dan Pustaka.

[2] Harvey M. Deitel and Paul J.Deitel, Java How to Program, ( $\left.8^{\text {th }} e d.\right)$, Prentice Hall, 2009.

[3] Hashim Haji Musa, Sejarah Perkembangan Tulisan Jawi-1 ${ }^{\text {st }}$ Edtion, Dewan Bahasa Dan Pustaka, 1999.

[4] Priestly, M. (2007). Practical Object-Oriented Design with UML. ( $2^{\text {nd }}$ ed.) U.K: The Mc Graw Hill.

[5] Bennet, S. , McRobb, S. \& Farmer, R. (2006). ObjectOriented System Analysis And Design Using UML $\left(3^{\text {rd }}\right.$ ed.). U.K: The Mc Graw Hill.

[6] Y.Daniel Liang, Introduction to Java Programming Language, $9^{\text {th }}$ Edition, Pearson Hall, 2012.

[7] Pak Matlob, (2005, October 23). (Ejaan Negeri Johor), Pintar Jawi Column, Berita Minggu.

[8] Pak Matlob, (2005, November 23). (Kaedah Menulis Jawi), VMet-Jawi Column, Harian Metro.

[9] Aoyama Toru; Professor, Faculty Of Foreign Studies, Tokyo University Of Foreign Studies. Annals of Japan Associon for Middle East Studies (AJAMES), no. 20-2, pp. 399-404, 2005. (Islamic Area Studies in Japan).

[10] Deitel, H.M. , Deitel, P.J. \& Santry, S.E. (2004). Advanced Java 2 Platform How to Program. New Jersey: Prentice Hall.

[11] Mashkuri Yaacob, Zainab A. N., Rohana Mahmud and Nor Edzan Che Nasir, Digitisation of an endangered written language: the case of the Jawi script, Proceeding of International Symposium on Language in Cyberspace, Korean National Commission for UNESCO, 2001

[12] Muhammmad Mun'im bin Ahmad Zabidi, (1994, September 27) (The Development of Jawi Character Set $1^{\text {st }}$ AFSIT 25 April 2004)

[13] Muhammmad Mun'im bin Ahmad Zabidi, Haliza Ibrahim (1994, September 27) (Text Processing in Malay, $7^{\text {th }}$. AFSIT)

[14] http://e-jawi.net/

[15] http://jawinet.8k.com/rumi/main.html

[16] http://www.ejawi.net/converter.php

[17] http://www.testingbrain.com/

[18] http://www.webopedia.com/TERM/A/authoring_tool.htm

[19] http://ncam.wgbh.org/salt/guidelines/sec10.html

[20] http://forum.java.sun.com/index.jspa

[21] http://www.microsoft.com/offi 